\title{
Does land irrigation actually reduce foraging habitat for breeding lesser kestrels? The role of crop types
}

\author{
Esperanza Ursúa ${ }^{a, *}$, David Serrano ${ }^{a, b, *}$, José L. Tella ${ }^{a}$ \\ ${ }^{a}$ Department of Applied Biology, Estación Biológica de Doñana (C.S.I.C.), Pabellon Del Peru, Avenida Maria, Luisa s/n, 41013 Sevilla, Spain \\ ${ }^{\text {b }}$ Population Ecology Group, Department of Natural Resources, Instituto Mediterráneo de Estudios Avanzados (CSIC-UIB), \\ c/Miquel Marques, 21, 07190 Esporles, Mallorca, Spain
}

\begin{abstract}
The lesser kestrel is a Globally Threatened Species which large decline has been related to recent agricultural changes in European pseudo-steppes. Irrigation is considered as one of the major threats for this and other steppe birds, but the actual effects of irrigation on foraging habitat selection have been scarcely examined. We studied the selection of traditional dry cereal farming and irrigated habitats by foraging lesser kestrels during the breeding cycle, paying especial attention to possible differences among crop types. Field margins were the scarcest but the most positively selected habitat, and different stages of cereals cultivated following traditional practices were selected depending on the breeding and agriculture cycles. Effects of irrigation were dual. While irrigated maize and other crop types were avoided, alfalfa was used in proportion to its availability and later highly selected after harvesting. Moreover, field margins in irrigated land were selected in a similar way than in traditional dry farmland. Therefore, although maintaining low-intensity farming is still the main recommendation for this species, new management options arise when social pressure makes irrigation unavoidable. Further agri-environmental schemes in these circumstances should thus promote cultivation of alfalfa with a low input of biocides while avoiding maize, together with increasing field margins, to make compatible irrigation with lesser kestrel conservation.
\end{abstract}

Keywords: Habitat selection; Irrigation; Falco naumanni; Crop types; Alfalfa; Field margins

\section{Introduction}

Agriculture intensification has been related to the dramatic decline of birds adapted to low-intensity farming systems (Donald et al., 2001). A case of special concern are Iberian pseudo-steppes, which hold a large proportion of species with unfavourable conservation status (Suárez et al., 1997). Pseudo-steppes are dominated by the extensive cultivation of cereals in flat landscapes on a 2-year rotational basis, resulting in mosaics

\footnotetext{
* Corresponding authors. Tel.: +34 95 4232340; fax: +34 95 4621125.

E-mail addresses: ursua@ebd.csic.es (E. Ursúa), serrano@ebd. csic.es (D. Serrano).
}

of cereal fields, stubbles, ploughed and fallow land, combined with sheep grazing. This system has changed dramatically in many areas looking for more profitable farming systems. These changes include a great reduction of fallow land and field margins, changes in crop types, sharply increases of irrigation lands, abuse of biocides and fertilizers, and the abandonment or afforestation of marginal lands (Suárez et al., 1997).

The lesser kestrel Falco naumanni has been used as a target species for examining the effects of agriculture intensification on bird conservation. This is a small, insectivorous falcon typically inhabiting Palearctic pseudo-steppes during the breeding season, being classified now as a Globally Threatened Species due to its major 
decline, especially in its European range (Tucker and Heath, 1994). Analyses of landscape features (Bustamante, 1997) and habitat selection studies (Donázar et al., 1993; Tella et al., 1998) suggested that the decline of the species in Spain was due to recent agricultural changes, while other hypotheses did not reach support (Negro et al., 1993; Forero et al., 1996; Rodríguez and Bustamante, 2003). There is also evidence for the negative impact of agricultural changes on the species in Portugal (Franco and Sutherland, 2004), Turkey (Parr et al., 1997), and Kazakhstan (Tella et al., 2004).

Land irrigation is one of the most important causes of alteration in pseudo-steppes, mainly through the intensification and change of crops, and a rise in the use of chemical compounds (Herrero and Snyder, 1997), being considered as one of the major threats for the conservation of steppe birds (Suárez et al., 1997). However, the impact of irrigation on bird populations has been scarcely assessed (Brotons et al., 2004). In the case of the lesser kestrel, evidence is restricted to the facts that its breeding densities were negatively related to the proportion of irrigated land in Southern Spain (Bustamante, 1997), and that wintering lesser kestrels significantly avoided newly irrigated fields in North Spain (Tella and Forero, 2000). It is largely unknown, however, whether all kind of irrigated crops are equally avoided, since previous studies pooled irrigated crop types. Our aim here was to assess the relative contribution of traditional dry cereal farming and irrigated land on foraging habitat selection during their breeding cycle, paying especial attention to differences among crop types to derive effective conservation strategies.

\section{Study area and methods}

We conducted this study on an area of ca. $250 \mathrm{~km}^{2}$ of Los Monegros (Bujaraloz-Peñalba, Ebro valley, NE Spain), where habitat selection of breeding lesser kestrels was previously studied (Tella et al., 1998; Tella and Forero, 2000). This area holds the largest local population of lesser kestrels (307 breeding pairs in the study year, 2002) of the Ebro valley (see Serrano and Tella, 2003). This valley has been historically transformed into a large pseudo-steppe devoted to dry cereal farming using traditional practices, such as the maintenance of fallows, little use of fertilizers and biocides, and the existence of numerous field margins. However, current irrigation plans are being developed to replace the cereal fallow system with intensive cultures (Herrero and Snyder, 1997; Tella et al., 1998).

Measures of habitat availability and selection were obtained following the same methodology used in winter 1997 (Tella and Forero, 2000). We choose an itinerary of $38 \mathrm{~km}$ of unpaved roads; the first plot of the itinerary $(65.5 \%)$ covered the proportion of dry-farmed land and the second $(34.5 \%)$ of irrigated crops. Colonies are widespread within both plots, so we do not expect any kind of bias due to their spatial distribution. The surfaces occupied by natural vegetation, salt lakes, field margins, and agriculture land were taken from Tella and Forero (2000), since their relative extent has remained largely constant in recent years. The proportion of surface occupied by each kind of crop within agriculture land, however, has greatly changed due to irrigation programs. We obtained it by linearly measuring the extension of crop types in both sides of the itinerary using the kilometer gauge in the car (Parr et al., 1997; Tella and Forero, 2000).

This itinerary was surveyed for foraging lesser kestrels by driving a car at a slow speed in good weather conditions. The almost linearly designed itinerary precluded us from sampling the same individual more than once on the same survey. Moreover, similar habitat selection patterns of radio-tracked individuals and temporal duration of the study guaranteed that our results were not biased by pseudoreplication (see Tella and Forero, 2000). We only recorded birds hovering or hunting from perches. When they were over a point situated at less than three meters from a field margin we assigned them to this habitat. If a foraging bird changed of habitat or field crop, we did not consider the new one to avoid pseudoreplication. No biases in the detectability of kestrels along the itinerary or among habitats are likely, given the flatness of the area and the short vegetation (Tella and Forero, 2000).

Both the availability of habitat and the selection made by lesser kestrels were studied in the mate feeding (last ten days of April) and the chick-rearing (from late June to late July) periods. Mate feeding has been shown to positively affect laying date and clutch size (Donázar et al., 1992), while nestling starvation due to food scarcity strongly affects breeding success (Tella et al., 1998; Rodríguez, 2004), thus justifying the study of habitat selection during both periods (Tella et al., 1998). Surveys were spaced at least 2-3 days to reduce the possibility of contagious events of habitat selection (e.g., the temporal upsurge of prey in a single crop field, Tella et al., 1998). Therefore, we obtained three surveys for the mate-feeding period and eleven surveys for the chick-rearing one.

Habitat selection in each sampling period was analysed using the Savage selectivity index $\mathrm{w}_{\mathrm{i}}=\mathrm{U}_{\mathrm{i}} / \mathrm{p}_{\mathrm{i}}$ (Tella and Forero, 2000), where $U_{i}$ is the proportion of observations recorded in a given habitat and $\mathrm{p}_{i}$ is the proportion of that habitat against total available habitat. This index varies from 0 (maximum negative selection) to $\mathbf{1}$ (maximum positive selection), 1 indicating no selection (Manly et al., 1993). The statistical significance of this index was obtained by comparing the statistic $\left(\mathrm{w}_{\mathrm{i}}-1\right)^{2} / \mathrm{se}\left(\mathrm{w}_{\mathrm{i}}\right)^{2}$ with the corresponding critical value of a $v^{2}$ distribution with one degree of freedom, the null 
hypothesis being that birds use habitats in proportion to its availability. The standard error of the index [se $\left.\left(\mathrm{w}_{\mathrm{i}}\right)\right]$

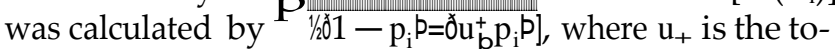
tal number of foraging records sampled (Manly et al., 1993). Statistical significance was obtained after applying the Bonferroni correction for the number of statistical tests.

\section{Results}

Most of the study area was occupied by agriculture, natural vegetation covering less than $8 \%$ of the surface.
Availability of different kind of crops and its stages varied slightly between April and July, as a result of progressing farming labours (see Figs. 1(a) and 2(a)). The most remarkable change was the almost disappearance of growing unirrigated cereals from April (when occupying $40 \%$ of the area) to July due to harvesting, being thus replaced by dry cereal stubble. Conversely, irrigated maize stubble $(15 \%)$ and irrigated ploughed fields $(5 \%)$ available in April disappeared in July and irrigated harvested alfalfa decreased from ca. $4-0.5 \%$, to be mostly replaced by growing maize (from $3.5 \%$ to $16 \%$ ) and growing alfalfa (from $3 \%$ to $13 \%$ ) in the same irrigated landholdings. The rest of agricultural land uses
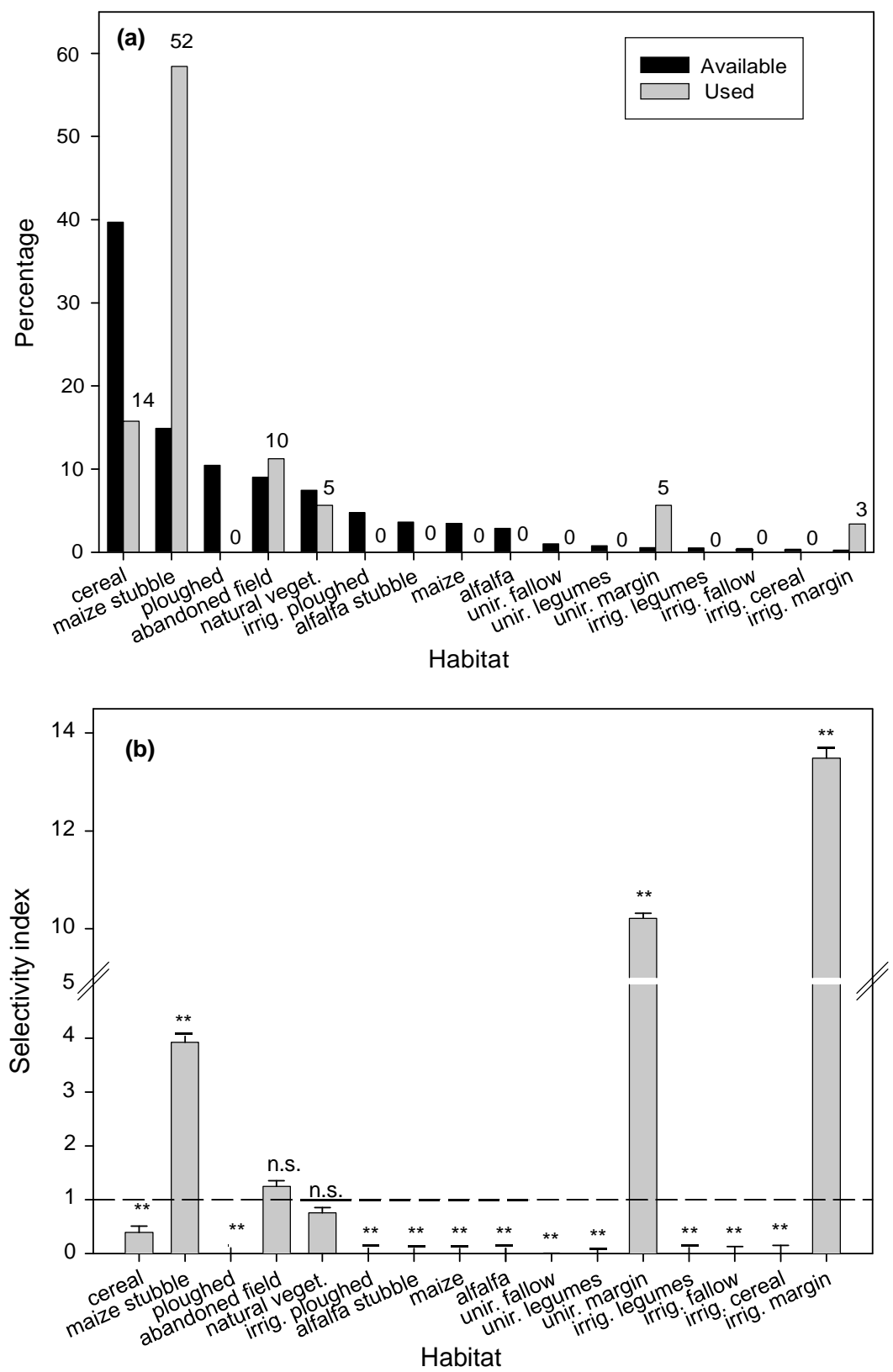

Fig. 1. (a) Proportion of habitat available and used by lesser kestrels (sample sizes above bars), and (b) values of the Savage selectivity index ( \pm se) for each habitat during the mate-feeding period. The horizontal line shows the index value $(=1)$ indicating no habitat selection. 

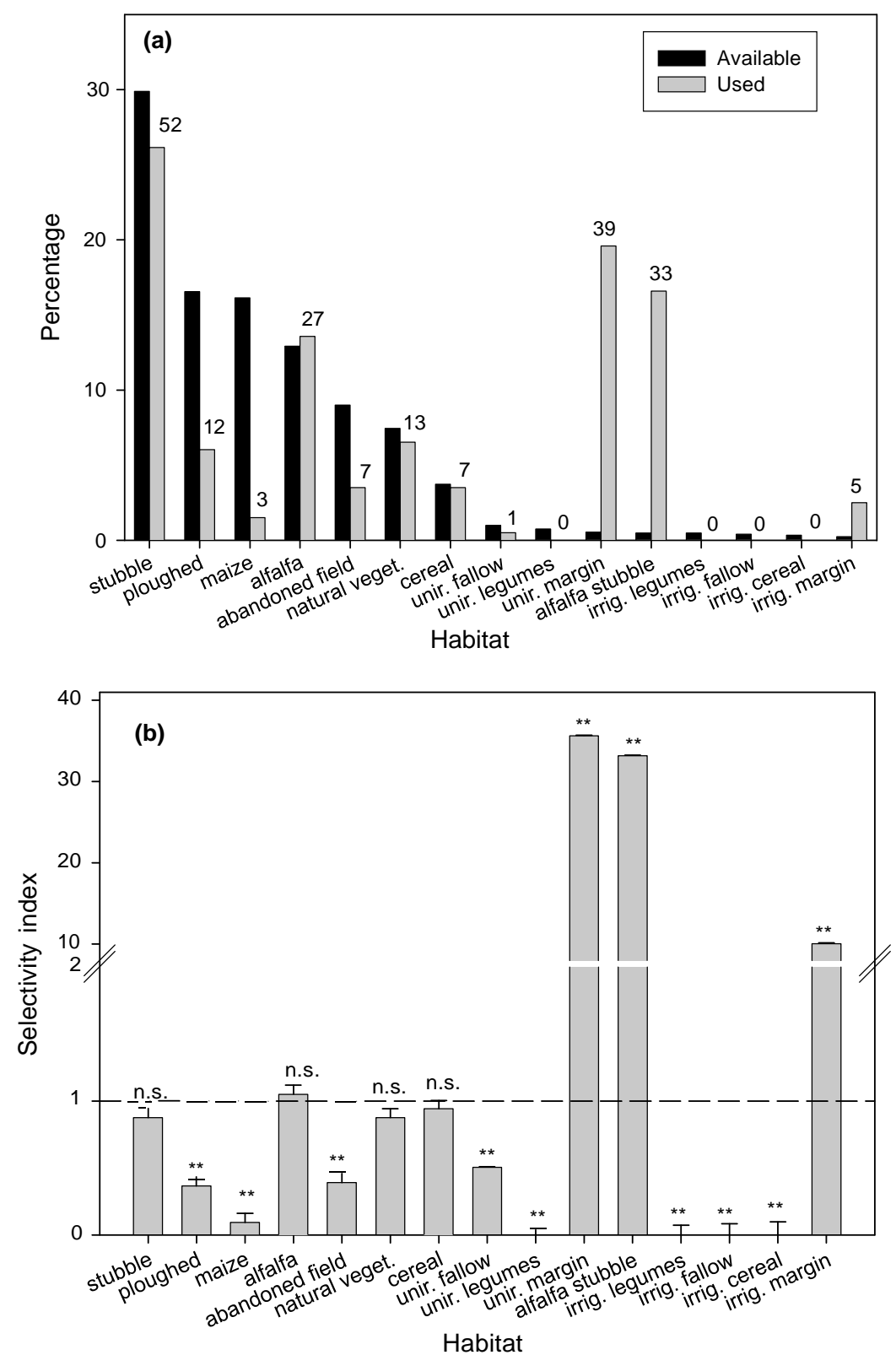

Fig. 2. (a) Proportion of habitat available and used by lesser kestrels (sample sizes above bars), and (b) values of the Savage selectivity index ( \pm se) for each habitat during the chick-rearing period. The horizontal line shows the index value $(=1)$ indicating no habitat selection.

remained rather constant between the two periods, with moderate (unirrigated ploughed fields: $11 \%$, abandoned fields: $9 \%$ ) to minor availability (long-term unirrigated fallows: $1 \%$, unirrigated legumes: $0.8 \%$, irrigated cereals: $0.3 \%$, irrigated cereal fallow: $0.4 \%$, irrigated legumes: $0.5 \%$ ). Field margins in dry and irrigated areas only occupied $0.55 \%$ and $0.25 \%$ of the available habitat, respectively.

A total of 288 observations of foraging lesser kestrels were registered, 89 of them during the mate-feeding period and 199 during the chick-rearing period. In April, lesser kestrels used significantly less than expected the most abundant habitat, i.e., unirrigated growing cereals $\left(\mathrm{w}_{\mathrm{i}}=0.40, \mathrm{se}\left(\mathrm{w}_{\mathrm{i}}\right)=0.11, \mathrm{p}<0.0001\right)$, while positively selected the smallest surfaces occupied by field margins both in unirrigated $\left(\mathrm{w}_{\mathrm{i}}=10.21\right.$, $\left.\mathrm{se}\left(\mathrm{w}_{\mathrm{i}}\right)=0.10, \mathrm{p}<0.0001\right)$ and irrigated areas $\left(\mathrm{w}_{\mathrm{i}}=\right.$ 13.48, $\left.\mathrm{se}\left(\mathrm{w}_{\mathrm{i}}\right)=0.19, \mathrm{p}<0.0001\right) \quad$ (Fig. 1). Irrigated maize stubbles were also used more than expected (Fig. 1(a)), although the selectivity index was much lower than in the case of field margins $\left(w_{i}=3.93\right.$, $\mathrm{se}\left(\mathrm{w}_{\mathrm{i}}\right)=0.11, \mathrm{p}<0.0001$; Fig. 1(b)). Natural vegetation and abandoned fields were used in proportion of its availability $\left(\mathrm{w}_{\mathrm{i}}=0.75\right.$ and 1.25 , respectively), while the rest of habitats were significantly avoided (all $\mathrm{w}_{\mathrm{i}}=0.00, \mathrm{p}<0.0001$; see Fig. 1(b)). 
Habitat selection changed somewhat between April and July. The most common habitat in April, unirrigated cereals, was now used in proportion to its availability both when still not harvested and later as stubble (Fig. 2). The scarcely represented field margins were again positively selected both in unirrigated $\left(\mathrm{w}_{\mathrm{i}}=\right.$ 35.33, $\left.\mathrm{se}\left(\mathrm{w}_{\mathrm{i}}\right)=0.06, \mathrm{p}<0.0001\right)$ and irrigated areas $\left(\mathrm{w}_{\mathrm{i}}=10.05, \mathrm{se}\left(\mathrm{w}_{\mathrm{i}}\right)=0.12, \mathrm{p}<0.0001\right)$. Irrigated alfalfa, however, was now selected after harvested $\left(\mathrm{w}_{\mathrm{i}}=33.17\right.$, $\left.\mathrm{se}\left(\mathrm{w}_{\mathrm{i}}\right)=0.07, \mathrm{p}<0.0001\right)$ as much as were field margins in unirrigated areas, while it was used in proportion to its availability when still growing (Fig. 2). Natural vegetation also was used in relation to its availability, while abandoned fields were now significantly avoided $\left(\mathrm{w}_{\mathrm{i}}=0.39, \mathrm{se}\left(\mathrm{w}_{\mathrm{i}}\right)=0.07, \mathrm{p}<0.0001\right.$; Fig. $\left.2(\mathrm{~b})\right)$. The rest of habitats were used significantly less than expected $\left(\mathrm{w}_{\mathrm{i}}\right.$ ranges $=0.00-0.50$, all $\mathrm{p}<0.0001$; see Fig. $\left.2(\mathrm{~b})\right)$.

\section{Discussion}

Agri-environmental programs have been extensively promoted by the European Common Agricultural Policy to alleviate the ecological impact of modern agriculture. However, results of these schemes have been not always effective (e.g., Kleijn et al., 2001; Suárez et al., 2004), due in part to a still insufficient understanding of wildlife habitat requirements and its responses to agriculture management. This study contributes to cover this need for a target pseudo-steppe species in two ways.

First, our results reinforce previous conclusions when studying habitat selection during the chick-rearing period by using a more accurate method (radiotelemetry) eight years ago in the same area (Tella et al., 1998) and, by extending the study to the pairing period, it supports the need of considering the whole annual cycle for designing adequate management actions (Tella and Forero, 2000; see also Blanco et al., 1998 for other species). Combining present with previous results, field margins constitute the preferred foraging habitat, although being the scarcest, for lesser kestrels along the annual cycle. Then, traditionallyfarmed cereals are selected depending of their crop stage and moment of the year. These habitats are always less preferred than field margins but, in turn, they quantitatively offer a much greater surface. Habitat preferences were related to the differential availability and/or accessibility (i.e., due to vegetation structure) of arthropod prey for lesser kestrels (Tella et al., 1998). Recent work has shown that habitat selection patterns correspond with the availability of prey in each habitat, being much higher in field margins than in crops (Rodríguez, 2004). All together, the promotion of field margins and the maintenance of a mosaic of low intensity, rotational cereal cultivation, avoiding land abandonment and afforestation, are again highlighted as the main recommendations for conserving lesser kestrel populations.

Second, we provide here a significant contribution to our ability to undertake effective action. Although irrigation has been expected as a major threat for this and other steppe bird species (Suárez et al., 1997; Tella et al., 1998; Tella and Forero, 2000; Brotons et al., 2004), we are showing here that it still may offer adequate foraging habitats. Field margins in irrigated and dry farming areas are selected in a similar way in both study periods, suggesting that abundance of suitable arthropods in margins is not greatly affected by irrigation, and that it may be partly independent of the crop types surrounding them. Some irrigated crops such as maize are avoided, given that its height $(1.6-2 \mathrm{~m})$ and uniformly dense vegetation cover preclude kestrels to capture prey (Donázar et al., 1993), and they are only punctually used once harvested. Irrigated alfalfa, however, offers an adequate vegetation structure (20-30 cm height) and thus is used in proportion to its availability during the chick-rearing period, being highly selected once harvested to reach similar levels than field margins in unirrigated areas (Fig. 2(b)). These results open new expectances for effective application of alternative agri-environmental management, taking into account the increasing pressure for implementing irrigation schemes.

Recent Spanish plans included the irrigation of 600,000 ha over the next few decades (Suárez et al., 1997), most of them affecting pseudo-steppe areas with a high ornithological interest (Suárez-Seoane et al., 2002; Brotons et al., 2004). For example, irrigation has yet substituted 101,480 ha of pseudo-steppe in the lesser kestrel breeding area in Aragon and will cover other ca. 18,000 ha more in the next four years. This figure is a relative conservation success given that about 100,000 ha were excluded from irrigation projects for the conservation of threatened steppe species such as the lesser kestrel. Therefore, when social pressure makes irrigation unavoidable, there is the new option to manage crop types. Agri-environmental schemes should promote cultivation of alfalfa while avoiding maize in areas relevant for this species (see also Wolff et al., 2002). Active management should also increase the surface of field margins in irrigated land. Finally, we must to take into account that irrigation is young in our study area, where there was no tradition for high biocide and fertiliser inputs (Tella et al., 1998) and probably are still few used by the same landowners. There is evidence that its higher utilisation in other intensively managed agrosystems drastically reduces the prey of lesser kestrels (Rodríguez, 2004). Therefore, the potential compatibility of irrigation with lesser kestrel conservation would be only possible by also promoting a low input of contaminants. 


\section{Acknowledgements}

This study was funded by program LIFE 2000NAT/ E/7297 "Conservación del Hábitat de Nidificación de Falco naumanni en Aragón". We thank M.G. Forero, R. Jovani, G. López, J. Blas, M. Alcaide and I. Pagán for their help.

\section{References}

Blanco, G., Tella, J.L., Torre, I., 1998. Traditional farming and key foraging habitats for chough Pyrrhocorax pyrrhocorax conservation in a Spanish pseudo-steppe landscape. Journal of Applied Ecology 35, 232-239.

Brotons, L., Mañosa, S., Estrada, J., 2004. Modelling the effects of irrigation on the distribution of steppe birds in Mediterranean farmland. Biodiversity and Conservation 13, 1039-1058.

Bustamante, J., 1997. Predictive models for lesser kestrel Falco naumanni distribution, abundance and extinction in Southern Spain. Biological Conservation 80, 153-160.

Donald, P.F., Green, R.E., Heath, M.F., 2001. Agricultural intensification and the collapse of Europe's farmland bird populations. Proceedings Royal Society London B 268, 25-29.

Donázar, J.A., Negro, J.J, Hiraldo, F., 1992. Functional analysis of mate-feeding in the Lesser Kestrel Falco naumanni. Ornis Scandinavica 23, 190-194.

Donázar, J.A., Negro, J.J., Hiraldo, F., 1993. Foraging habitat selection, land-use changes and population decline in the lesser kestrel Falco naumanni. Journal of Applied Ecology 30, 515-522.

Forero, M.G., Tella, J.L., Donázar, J.A., Hiraldo, F., 1996. Can interspecific competition and nest site availability explain the decrease of lesser kestrel Falco naumanni populations?. Biological Conservation 78, 289-293.

Franco, A.M.A., Sutherland, W.J., 2004. Modelling the foraging habitat selection of lesser kestrels: conservation implications of European Agricultural Policies. Biological Conservation 120, 6374.

Herrero, J., Snyder, R.L., 1997. Aridity and irrigation in Aragón, Spain. Journal of Arid Environments 35, 535-547.

Kleijn, D., Berendse, F., Smit, R., Gilissen, N., 2001. Agri-environment schemes do not effectively protect biodiversity in Duth agricultural landscapes. Nature 413, 723-725.

Manly, B.F.J., McDonald, L.L., Thomas, D.L., 1993. Resource Selection by Animals. Chapman and Hall, London.
Negro, J.J., Donázar, J.A., Hiraldo, F., Hernández, L.M., Fernández, M.A., 1993. Organochlorine and heavy metal contamination in non-viable eggs and its relation to breeding success in a Spanish population of lesser kestrels (Falco naumanni). Environmental Pollution 82, 201-205.

Parr, S.J., Naveso, M.A., Yarar, M., 1997. Habitat and potential prey surrounding lesser kestrel Falco naumanni colonies in central Turkey. Biological Conservation 79, 309-312.

Rodríguez, C., Bustamante, J., 2003. Effects of weather on lesser kestrel breeding success: can climate change explain historical population declines?. Journal of Animal Ecology 72, 793-810.

Rodríguez, C., 2004. Factores ambientales relacionados con el éxito reproductivo del cernícalo primilla. Cambio climático e intensificación agraria. PhD Thesis, University of Salamanca, Spain.

Serrano, D., Tella, J.L., 2003. Dispersal within a spatially structurated population of lesser kestrels: a role of spatial isolation and conspecific attraction. Journal of Animal Ecology 72, 400-410.

Suárez, F., Naveso, M.A., De Juana, E., 1997. Farming in the drylands of Spain: birds of the pseudosteppes. In: Pain, D., Pienkowski, M.W. (Eds.), Farming and Birds in Europe. Academic Press, London, pp. 297-330.

Suárez, F., Garza, V., Oñate, J.J., García de la Morena, E.L., Ramírez, A., Morales, M.B., 2004. Adequacy of winter stubble maintenance for steppe passerine conservation in central Spain. Agriculture, Ecosystems and Environment, in press.

Suárez-Seoane, S., Osborne, P., Alonso, J.C., 2002. Large-scale habitat selection by agricultural steppe birds in Spain: identifying specieshabitat responses using generalized additive models. Journal Applied Ecology 39, 755-771.

Tella, J.L., Forero, M.G., Hiraldo, F., Donázar, J.A., 1998. Conflicts between lesser kestrel conservation and European agricultural policies as identified by habitat use analyses. Conservation Biology 12, 593-604

Tella, J.L., Forero, M.G., 2000. Farmland habitat selection of wintering lesser kestrels in a Spanish pseudosteppe: implications for conservation strategies. Biodiversity and Conservation 9, 433441.

Tella, J.L., Carrete, M., Sánchez-Zapata, J.A., Serrano, D., Gravilov, A., Sklyarenko, S., Ceballos, O., Donázar, J.A., Hiraldo, F., 2004. The role of land-uses, nesting-site availability, and the presence of avian predators on the distribution of breeding lesser kestrels in Kazakhstan. Oryx 38, 224-227.

Tucker, G.M., Heath, M.F., 1994. Birds in Europe: their conservation status. BirdLife Conservation Series 3, Cambridge.

Wolff, A., Dieuleveut, T., Martin, J.-L., Bretagnolle, V., 2002. Landscape context and little bustard abundance in a fragmented steppe: implications for reserve management in mosaic landscapes. Biological Conservation 107, 211-220. 